\title{
Guiding the healing of suicide survivors
}

\author{
Touched by suicide: hope and healing \\ after loss \\ Michael F. Myers and Carla Fine \\ Gotham Books; 2006 \\ 320 pp Can\$19.50 ISBN 1-592-40228-3
}

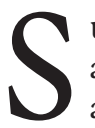
udden death, from any cause, and sudden death from suicide are neighbours, and yet worlds apart. Both are devastating losses for families; however, suicide, unlike other causes of death, can infuse the people connected, commonly referred to as suicide survivors, with unrelenting guilt and profound isolation. As a family physician, you might anticipate having I suicide every $3-4$ years in your practice. Any physician may be uniquely positioned to assist in a family's healing from their loss due to suicide. Touched by Suicide, a new book by Dr. Michael Myers and Carla Fine, is an excellent tool to aid survivors suffering from the loss of a family member to suicide.

Touched by Suicide makes a unique contribution to the books available on surviving after a suicide by combining the perspectives of Myers, a mental health professional, and Carla Fine, a survivor of the suicide of a close family member. The book demonstrates the power of a partnership between scientific knowledge and the wisdom of lived experience. - The authors' compassion and concrete advice provide a sturdy handrail for people trying to help families climbing out of the abyss following their loved one's suicide, particularly, in the later stages of grief.

Myers is a well-known Canadian

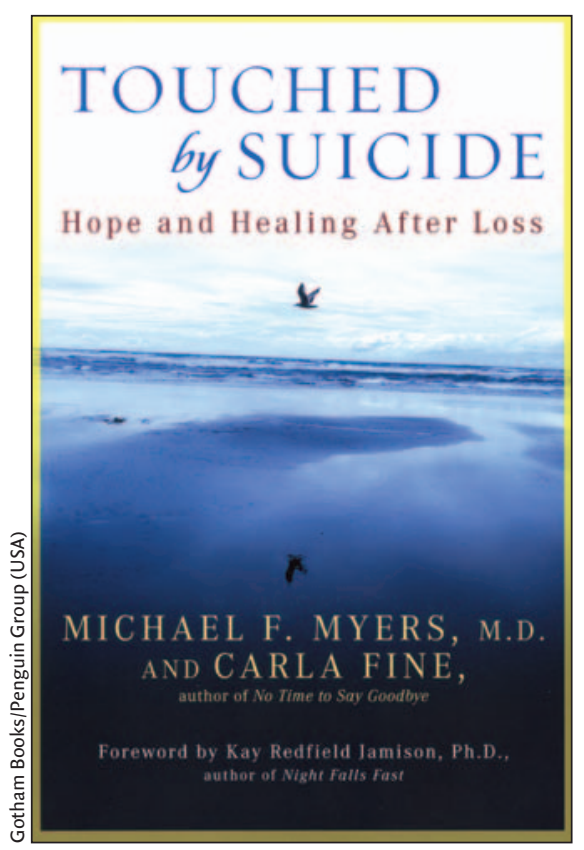

psychiatrist who has an international reputation for his work in the prevention of physician suicide, and with physicians suffering from mental illness.

Since Fine's husband - a prominent urologist in New York City - took his life in 1989 , she has become a significant advocate for suicide survivors. Her previous book on surviving suicide, No Time to Say Goodbye, seems especially helpful for survivors early on in the healing process.

In addition to these 2 authors, Touched by Suicide gives voice to dozens of survivors who share their stories about their journey of healing.

The book is organized into 3 parts, beginning with "What Happened? The Aftermath of Suicide," which presents the range of reactions resulting from a loved one's suicide, including anger, depression, dissociative symptoms to full blown post-traumatic stress disorder. The book offers poignant insights such as "Be prepared for the second year to be the most difficult. The shock is starting to wear off, and you're beginning to feel the pain full-force" (p. 30). "Survivors are consumed by the "why" of suicide. We look for answers ... as if trying to unravel a murder mystery that we instinctively realize will never be solved" (p. 35). "The 'real' reason dies with our loved one, and we are left behind - feeling helpless and guilty and ineffective - to try to put the pieces of an unsolvable puzzle back together" (p. 36). The authors also provide sound advice on dealing with and comprehending suicide notes. However, their central tenet concerns the need for survivors to connect with other survivors to receive the support and guidance to heal.

Part 2 deals with the practical necessities of the healing following a suicide that are often not covered in any depth in other books. The authors discuss various strategies to protect an individual survivor's health, to help the family to come together following a suicide and to choose an appropriate mental health professional to assist in the healing. A particularly useful chapter guides survivors about the issue of talking to surviving children about a suicide. "You must tell your children the truth in an age-appropriate manner from the beginning, no matter how young they are" (p. I25). They even provide sample language to initiate the discussion.

Part 3 deals with "Finding Meaning After Suicide" and discusses how many survivors find religion, spirituality and 
advocacy as a way to transform life after suicide.

The book contains quotes from Oregon Senator Gordon Smith and his wife Sharon who lost their son Garrett to suicide. As part of the US National Strategy for Suicide Prevention, the Smiths led the initiative to develop suicide prevention programs at colleges and universities. The Garrett Lee Smith Memorial Act was signed into law in October 2004.

Canada could benefit from similar survivor advocacy in order to continue the momentum necessary to creating a national suicide prevention strategy. Unfortunately, Canada remains one of the few developed nations without a national suicide prevention strategy. The good news is that Canadian survivors are moving from grief to action. The Canadian Association for Suicide Prevention (CASP), a well-integrated organization of health care practitioners and survivors, has developed the CASP Blueprint for a Canadian $\mathrm{Na-}$ tional Suicide Prevention Strategy. In May 2006, the Standing Senate Committee on Social Affairs, Science and Technology's report, Out of the Shadows at Last, called upon the federal government to support the efforts of CASP and other organizations working to develop a national suicide prevention strategy. The contact information for CASP (www.suicideprevention.ca) and other advocacy organizations are given in the resource directory of the book.

Touched by Suicide is moving and well produced. I had only a few minor criticisms. The book is targeted at an American audience and some Canadian resources for survivors, such as the Survivor Listserve (SurvivorAdvocatessubscribe@yahoogroups.com) created by the Canadian Association for Suicide Prevention, are noticeably missing. Initially designed to connect "Survivors in Action," the Listserve membership has evolved to also include health care practitioners interested in suicide prevention.

The book also covers some obscure topics, such as police suicides and murder/suicide. I wish the authors had used the room to provide more information about common psychiatric dis- orders related to suicide such as schizophrenia and borderline personality disorder.

In addition, when the authors are discussing the genetic risk for suicide, they need to make it clearer that research suggests that the risk for suicide seems to be inherited independent of the risk for psychiatric disorders. For example, you can find families with a heavy familial loading for bipolar disorder but no increased risk for suicide.

Physicians must be prepared to cope with the aftermath of a suicide among their patients and to offer guidance to the family surviving and needing to heal from this loss. This new book by Myers and Fine will be an invaluable resource to assist physicians in one of their most difficult but impactful roles: guiding the healing of suicide survivors.

Paul S. Links

Psychiatrist

Arthur Sommer Rotenburg Chair

in Suicide Studies

University of Toronto

Toronto, Ont.

\section{Poem}

\section{All the ward's a stage: a surgeon's sonnet}

Too soon the curtain of this stage will rise Well trained am I and in this role well versed

In readiness again I don my guise

Yet fear and trembling parch my throat with thirst

My face assumes a self assured masque

The company does not suspect I feign

I force myself to focus on the task

I must find strength to play my part again.

In spite of every effort tried last night

That blackest of all curtains dark did fall

Today we must continue in the fight

Returning to the spotlights of the hall.

One last attempt to calm my trembling heart

Then off I go to play my fateful part.

As physicians we try to distance ourselves emotionally from our work, but find there are always cases that affect us. Sometimes things do indeed go very wrong, despite our best preparations and intentions. No matter how humbling the event, we often have no choice but to return and perform the same procedure.

Wai Pui Ng
Deurosurgeon
Lepartment of Clinical Neurological
Sciences
London Health Sciences Centre

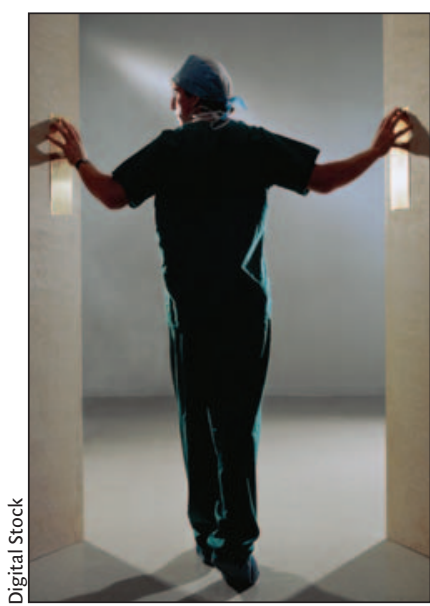

